\title{
FROM BIOREFINERY BY-PRODUCT TO BIORESINS. THERMOSETS BASED ON HUMINS AND EPOXIDIZED LINSEED OIL
}

\author{
EROL LICSANDRU and ALICE MIJA \\ Université Côte d'Azur, Université Nice-Sophia Antipolis, Institut de Chimie de Nice, \\ UMR CNRS 7272, 06108 Nice Cedex 02, France \\ 区 Corresponding author: Alice Mija, Alice.MIJA@unice.fr
}

Dedicated to the $70^{\text {th }}$ anniversary of the Department of Pulp and Paper, "Cristofor Simionescu" Faculty of Chemical Engineering and Environmental Protection, "Gheorghe Asachi" Technical University of Iasi

\begin{abstract}
Resource depletion is one of the hardest challenges facing humanity today. Reuse, repurposing and waste management are valid strategies in order to relieve some of the pressure on natural resources. For the first time, in this work, we propose to study the properties of bioresins synthesized by the combination of a lignocellulosic based by-product, humins $(\mathrm{Hu})$, and a vegetable resourced comonomer, epoxidized linseed oil (ELO). The copolymerization of these two bio-based products was conducted with the help of a common hardener, Capcure. The synthesized bioresins display a range of mechanical properties, from elastomers to rigid thermosets, showing their ability for industrial applications.
\end{abstract}

Keywords: renewable resources, biorefinery by-products, humins, epoxidized linseed oil

\section{INTRODUCTION}

The European strategy of development envisages a bio-based economy founded on locally sourced and produced plant and waste derived materials, chemicals, fuels, food and feed. This global paradigm shifting from oil-based towards bio-based materials represents a unique opportunity for Europe to kick-start a world leading competitive bio-economy with significant financial, environmental and societal benefits. The EU, with its strong agricultural, agro-food and forest-based sectors and world leading companies in the plant breeding, biotech, renewable energy and chemical/biochemical industries, is technologically poised to spearhead the development of a bio-based economy with a global market value of $€ 200$ bn by 2020 . Therefore, the research and innovation in the biobased materials area have the aim to support the transition towards more efficient energy building by means of reducing the dependence on fossil resources. For this application, the target is to obtain bioresins with the higher amount of biobased percentage. In this study, we focus on the elaboration of by-products based resins and their elaboration by applying the principles of green chemistry and circular economy. This study was done in the frame of LIFE15 ENV/BE/000204 project "RECYSITE", which aims to demonstrate the recyclability and reuse of a new generation of high-performance fibre-reinforced thermoset composites from renewable resources (bio-waste). In this perspective, we have focused on developing bioresins starting from renewable products for the eco-design of novel biobased materials.

The design of the bioresin materials has been done by choosing the main components: humins (Hu), a by-product from bio-refineries, and epoxidized linseed oil (ELO), an epoxy derivative of natural polyunsaturated linseed oil. The main component of these designed formulations is represented by humins, a biorefinery side product. Despite the fact that this product, resulting from prolonged sugar degradation reactions in the caramelisation process, is known for almost a century, $^{2-3}$ its applications are limited to energy and heat conversion. ${ }^{4-6}$ Recently, we have shown in our initial work that humins can be successfully used to produce polymeric foams. ${ }^{7-8}$ The polyfuranic structure of humins and its high 
functionality are important structural factors that should be considered and even exploited in order to develop interesting bio-based thermoset materials, ${ }^{9-10}$ or as a matrix for impregnations and composites. ${ }^{11-12}$

Humins are heterogeneous amorphous biomacromolecules, with a model structure constituted by furan rings connected via alkylene moieties, as proposed by van Zandvoort et al. ${ }^{13}$ and schematized in Figure 1. Although the interest is high, rarely materials have been elaborated from humins or humin derivatives, such as humin foams. ${ }^{7}$ In one such case, they have been employed as a low-cost complement for polyfurfuryl alcohol (PFA) in thermosetting resins. The resins were used to impregnate filter paper, and composites were obtained. The composites presented twice the tensile strength of composites elaborated using neat PFA or a PFA/lignin blend. Bio-based and bio-sourced materials employing epoxidized vegetable oils are much more prevalent. Vegetable oils are valuable platform chemicals for high performance materials due to their global availability and diversity. ${ }^{14-20}$ ELO was employed as the main component for thermosetting resins by crosslinking with anhydrides. ${ }^{21-26}$ Resins with biosourced content of up to $60 \%$ for MHHPA and to $70 \%$ for BTDA were obtained. ${ }^{27}$ Bio-sourced resins present decomposition temperatures similar to those of commercially available DGEBA-based epoxy resins.

Taking into account these previous results, the strategy proposed in this work is a next step, i.e. the design and manufacturing of a bioresin based on humins and ELO. To copolymerize the two products, a third component was included in the formulations as a common hardener: Capcure 3800. Capcure 3-800 is sold as a low-temperature, industrial epoxide hardener. One of its main characteristics is that a tertiary amine-based initiator is not required with this hardener. This property allows the conception of eco-friendlier materials, since no initiators/catalysts are required. Figure 1 displays the chemical structure of the feedstock used in the conception of the bioresins.

In order to optimize the maximum humins content in the bioresin formulations, different $\mathrm{HU} / \mathrm{ELO} / \mathrm{Cap}$ ratios were tested, as presented in Table 1.
Structural insights into the copolymerization mechanism of $\mathrm{Hu} / \mathrm{ELO} / \mathrm{Cap}$ have been thoroughly provided in a previous work (not yet published), showing the formation of a bioresin terpolymer.

In this study, the thermo-mechanical properties of the obtained bioresins are studied, in order to highlight their ability to generate materials with industrial application potential. The thermomechanical properties of the bioresins have been analyzed by rheometry, dynamic mechanical analysis (DMA), Shore tests and the thermal resistance of these polymers has been evaluated by thermogravimetry (TGA).

\section{EXPERIMENTAL} Materials

A commercially available bio-based epoxy molecule was obtained from Valtris Ltd. It is an epoxidized linseed oil (ELO), which is viscous-liquid at room temperature, having a viscosity of about 1200 mPa.s. ELO has a molecular weight of about 980 g.mol ${ }^{-1}$ and contains about 5.5 epoxy groups, on average.

Humins (Hu) were provided by Avantium Chemicals, as produced at the Avantium pilot plant in Geleen (Netherlands). These humin oligomers have molecular masses that generally range from 270 to 650 g. $\mathrm{mol}^{-1}$.

CAPCURE ${ }^{\circledR}$ 3-800 (CAP) is a mercaptanterminated product used as a liquid curing agent with unique rapid-cure characteristics for epoxy resins at ambient temperatures provided by Gabriel Performance Products.

\section{Sample preparation}

For the synthesis of the resins, multiple formulations and parameters have been assessed. The aim of this research was to accommodate formulations with a large content of humins. The humins were preheated at $80{ }^{\circ} \mathrm{C}$, then the hardener, in the specified proportions, was added to the humins and the mixture was well homogenized for 5 to 10 minutes. Thereafter, it was heated to $130{ }^{\circ} \mathrm{C}$ and stirred at this temperature for 20 minutes. To the hot mixture, ELO was added and incorporated. The homogenous mixture was then poured into the molds and kept in an oven at $130{ }^{\circ} \mathrm{C}$ for four hours. This crosslinking protocol is consistent with the results of curing, postcuring followed by DSC analyses.

To prepare the DMA specimens, the pre-polymer was put in a mold of $48 \times 8 \times 4 \mathrm{~mm}^{3}$ (length $\mathrm{x}$ width $\mathrm{x}$ thickness) and heated firstly to $80{ }^{\circ} \mathrm{C}$ under pressure of 10 bars for two hours. Then, the material was heated to $130{ }^{\circ} \mathrm{C}$ for $60 \mathrm{~min}$ to ensure completion of the curing. 

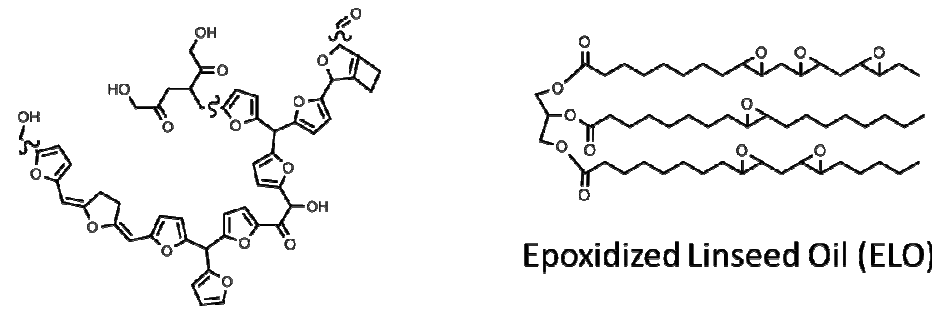

Epoxidized Linseed Oil (ELO)

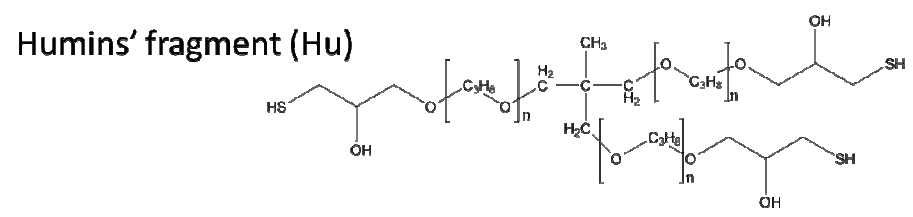

Capcure 3-800 (C)

Figure 1: Chemical structures of humins (Hu), epoxidized linseed oil (ELO) and Capcure 3-800

Table 1

Resin formulations based on humins, ELO and Capcure

\begin{tabular}{cccc}
\hline $\begin{array}{c}\text { Humins, } \\
\text { wt } \%\end{array}$ & $\begin{array}{c}\text { Capcure, } \\
\text { wt } \%\end{array}$ & $\begin{array}{c}\text { ELO, } \\
\text { wt } \%\end{array}$ & $\begin{array}{c}\text { Sample } \\
\text { code }\end{array}$ \\
\hline 30 & 52.5 & 17.5 & $30 \mathrm{Hu}$ \\
40 & 45 & 15 & $40 \mathrm{Hu}$ \\
50 & 37.5 & 12.5 & $50 \mathrm{Hu}$ \\
60 & 30 & 10 & $60 \mathrm{Hu}$ \\
\hline
\end{tabular}

\section{Experimental techniques Rheometry}

Rheological measurements were performed using an Anton Paar MCR-302 rheometer, using disposable plate-plate geometries $(25 \mathrm{~mm}$ diameter and $1 \mathrm{~mm}$ gap). The measurements were carried out at a scan rate of $0.2^{\circ} \mathrm{C} \cdot \mathrm{min}^{-1}$ over a temperature range from $80{ }^{\circ} \mathrm{C}$ to $200{ }^{\circ} \mathrm{C}$. Complex viscosity, storage modulus $\left(\mathrm{G}^{\prime}\right)$ and loss modulus (G") were measured by oscillatory shear experiments with an angular frequency of $10 \mathrm{rad} . \mathrm{s}^{-1}$ and a deformation of $0.2 \%$. The temperature of crossover of the values of storage ( $\left.\mathrm{G}^{\prime}\right)$ and loss (G”) moduli was considered as the temperature of gelation (Tgel).

\section{Thermogravimetric analysis}

The thermal stabilities of the obtained bioresins were analyzed using thermogravimetric analysis (TGA). The thermal degradation, mass loss and its derivative as a function of temperature were evaluated using a Mettler-Toledo TGA2 between $25^{\circ} \mathrm{C}$ and 1000 ${ }^{\circ} \mathrm{C}$ under oxidative (air) flow $\left(50 \mathrm{~mL} \cdot \mathrm{min}^{-1}\right)$ at a heating rate of $10{ }^{\circ} \mathrm{C} \cdot \mathrm{min}^{-1}$. Samples of about 5-10 mg were placed into $70 \mu \mathrm{L}$ alumina pans and tested.

\section{Dynamic mechanical analysis}

DMA measurements were performed in a MettlerToledo DMA1, equipped with a three-point bending assembly, at an oscillatory frequency of $1 \mathrm{~Hz}$ and an amplitude of $20 \mu \mathrm{m}$. The analyzed samples had rectangular dimensions of $48 \times 8 \times 4 \mathrm{~mm}^{3}$ (length $\mathrm{x}$ width $\mathrm{x}$ thickness). Each resin formulation was analyzed 3 times and the values were averaged. The DMA was operated in the temperature-scanning mode with a constant displacement amplitude and frequency. The temperature ramp covered a range from -50 to 120 ${ }^{\circ} \mathrm{C}$, at a heating rate of $3{ }^{\circ} \mathrm{C} \cdot \mathrm{min}^{-1}$ under nitrogen atmosphere. The loss (E”), storage (E') Young moduli and damping factor ( $\tan \delta=\mathrm{E}^{\prime} / \mathrm{E}$ ') were determined.

\section{Shore hardness test}

A Zwick Roell 3116 hardness device was used to determine the hardness according to ISO 7619-1 ASTM D2240 and ISO 868. To avoid errors, five samples of each bioresin formulation were tested, and three measurements have been done for each sample.

\section{RESULTS AND DISCUSSION Rheometry analysis during crosslinking}

Chemo-rheological studies were done in order to follow the chemical reactivity of the elaborated mixtures and also to identify the physical phenomena accompanying network formation, i.e. gelation and vitrification. The results of this study for the four formulations are presented in Figure 2 , showing the evolution of $G$ ' and $G$ " moduli during crosslinking of the systems. We can 
observe that the humin-based reactive mixtures start to react in the interval of $117-149{ }^{\circ} \mathrm{C}$, when heated at $0.2{ }^{\circ} \mathrm{C} \cdot \mathrm{min}^{-1}$, depending on the formulation composition. Also, it can be noticed that the system with the higher content of humins $(60 \%)$ starts reacting at a lower temperature, around $\sim 100{ }^{\circ} \mathrm{C}$, with a gelation point at $\sim 117^{\circ} \mathrm{C}$, in contrast with the system richer in ELO (30\% of humins), which starts reacting at around 120-130 ${ }^{\circ} \mathrm{C}$ with a gelation at around $150{ }^{\circ} \mathrm{C}$.

\section{Investigation of bioresins properties Thermomechanical properties}

DMA analyses were performed to analyze the molecular dynamics of the humin-based bioresins, especially the $\alpha$ relaxation phenomenon. Depending on the bioresin formulation/composition and temperature, some events can occur during mechanical solicitation, such as energy dissipation and mechanical transition. The values of maximum $\tan \delta$ are assigned to the $\alpha$ relaxation $\left(\mathrm{T}_{\alpha}\right)$ phenomenon, related to cooperative chain motions and associated with the macroscopic $\mathrm{T}_{g}$. As presented in Figure 3 and Table 2, the synthesized bioresins

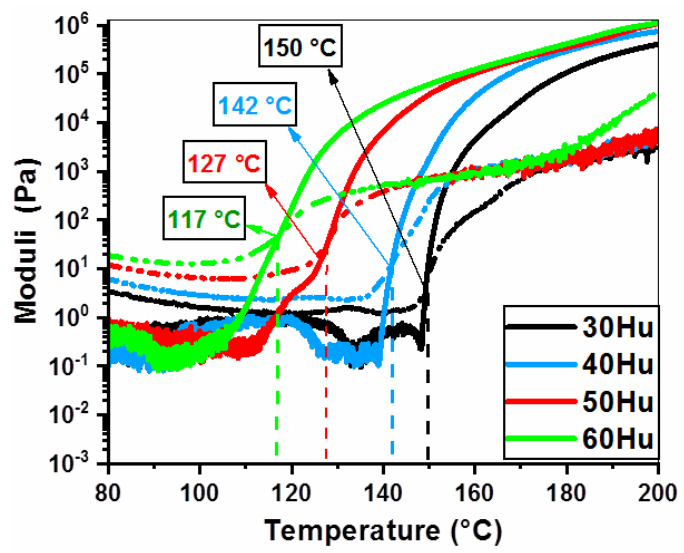

Figure 2: Evolution of moduli of humin-based mixtures during heating from 80 to $200{ }^{\circ} \mathrm{C}$ at $0.2^{\circ} \mathrm{C} \cdot \mathrm{min}^{-1}$

The DMA results were compared with those of DSC (second curing heating to measure the $T_{g}$ ) and with the hardness test results, as presented in Table 2. We can observe that the three techniques conduct to results that are in agreement, $\mathrm{Tg}$ values measured by DSC and the hardness of the bioresins follow the same trend as the $\tan \delta$ values. By Shore hardness tests, the resistance of have a broad interval of $\tan \delta$, from $\sim 10$ to $60{ }^{\circ} \mathrm{C}$, showing the potential of the proposed formulations to produce materials from elastic to rigid ones.

The symmetrical Gaussian shape of the $\tan \delta$ peak of " $30 \mathrm{Hu}$ " and " $40 \mathrm{Hu}$ " bioresins is an indication of the homogeneous distributions of relaxation times in the chain motions of the polymer. Increasing the humin content in the formulations produces an increase of the chain relaxation times, which is reasonable, considering the particularities of the humin structure. Then, the presence of a single $\tan \delta$ peak in each DMA curve is also a sign of homogeneous networking during terpolymerization. Then, we can observe in Figure 3 that the bioresins with lower content of humins (30\%) have higher amplitude of damping, i.e. higher peak height that could be related to the facility of chain motions, the high content of triglyceride chains of ELO playing the role of plasticizer between the humins core and increasing the energy dissipation by internal frictions. In consequence, the impact strength increases due to better dissipation of vibrational energy during impact.

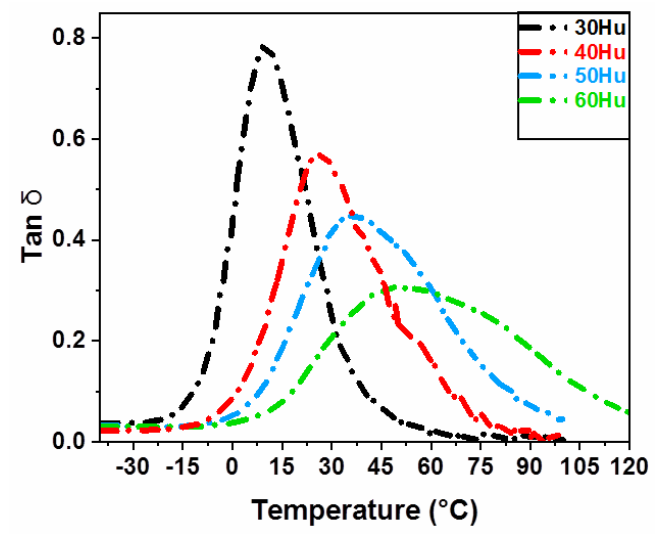

Figure 3: DMA plot for humin-based bioresin systems from -50 to $120^{\circ} \mathrm{C}$ at $3^{\circ} \mathrm{C} \mathrm{min}^{-1}$ and $1 \mathrm{~Hz}$

the bioresins was measured upon the penetration of a spring-loaded needle-like indenter. The Shore hardness results of the synthesized bioresins show values from 64A to 49D. According to the Shore hardness scale, the first value corresponds to a more elastic material, while the hardness of the bioresins with higher content of humins (60\%) corresponds to more rigid, hard materials. 
Table 2

Comparison of mechanical properties of humin bioresins according to DMA, DSC and Shore hardness test analyses

\begin{tabular}{lccc}
\hline Bioresin & $\tan \delta$ & $T_{g}$, DSC & Hardness \\
\hline $30 \mathrm{Hu}$ & 10 & -3 & $64 \mathrm{~A}$ \\
$40 \mathrm{Hu}$ & 28 & 11 & $74 \mathrm{~A}$ \\
$50 \mathrm{Hu}$ & 37 & 17 & $40 \mathrm{D}$ \\
$60 \mathrm{Hu}$ & 60 & 30 & $49 \mathrm{D}$ \\
\hline
\end{tabular}

\section{Thermal stability of the networks}

Thermogravimetric analyses were carried out to measure the thermal stability of the fully crosslinked materials under oxidant (air) flow. The TGA results of analyzed bioresins are given in Figure 4. The temperature of degradation was considered at $5 \%$ of the weight loss, $\mathrm{T}_{5 \%}$. The thermal degradation of the four bioresins involves complex chemical and thermo-oxidative multistep mechanisms. Surprisingly, the obtained results reveal a higher thermal stability for the ELO rich systems. We would expect that the presence of humins in the bioresin formulation should increase the thermal stability by the polyfuranic network. It wasn't the case, since the bioresin with $60 \%$ humins content had a lower thermal stability with a $\mathrm{T}_{5 \%}$ value of $\sim 250{ }^{\circ} \mathrm{C}$, compared with $\sim 300{ }^{\circ} \mathrm{C}$ for the $30 \%$ humins bioresin. Perhaps, we can explain this result by the high content of oxygen functions in humins, so we would expect an easier cleavage of ether links.

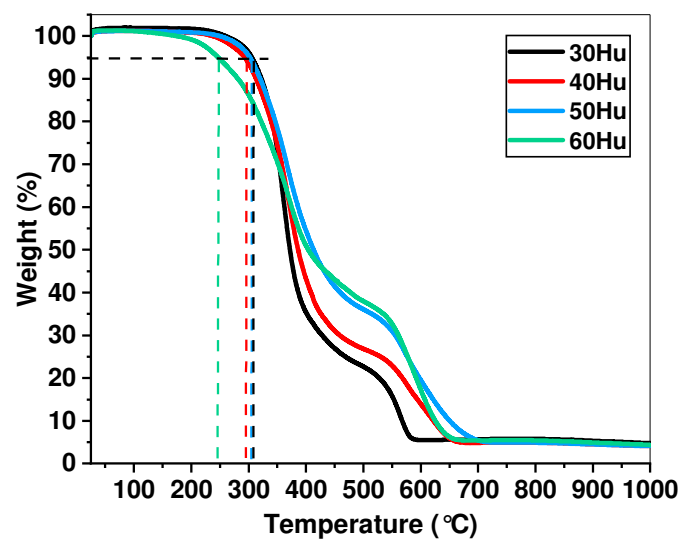

Figure 4: Thermogravimetric analysis of humin-based bioresin systems at $10{ }^{\circ} \mathrm{C} \cdot \mathrm{min}^{-1}$ under air

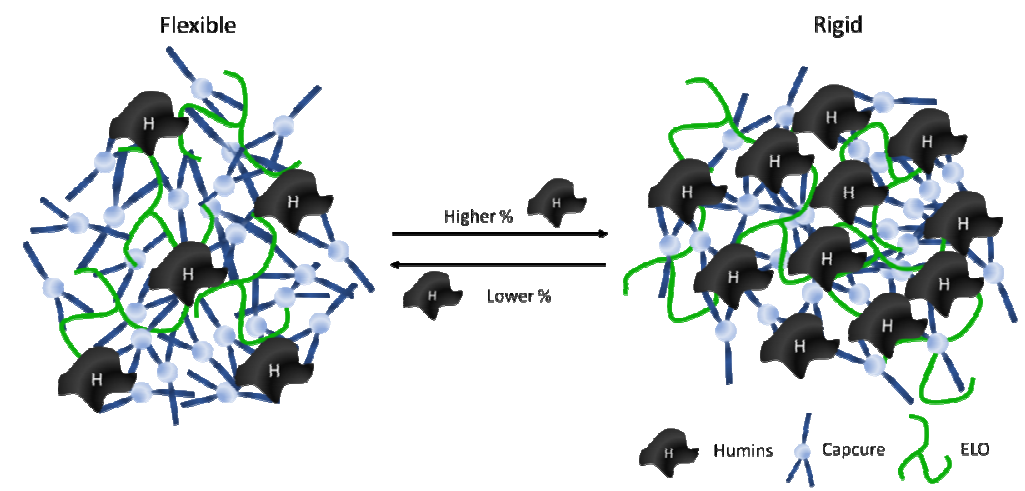

Figure 5: Humins-Capcure-ELO schematized networks

As presented in our previous study (not yet published), regarding the reaction mechanisms part, there are several possibilities of chemical reactions between the humins, ELO and Capcure. This freedom of each component to form chemical bonds with other components implies 
that the ratio of the reagents can be varied over a wide interval, between 30 and $60 \%$ weight in humins, yielding bioresin materials in each case. This variety of compositions allows a very good control over the final properties of the resulting material. The mechanical properties of the resin formulations vary with the proportion of humins present in the material. A formulation rich in humins is more rigid, while a formulation with a lower percentage of humins is more flexible, as schematized in Figure 5. The tuning of mechanical properties in the formulation phase is a very enticing advantage for thermosetting resins, as they can be optimized for the desired purpose.

\section{CONCLUSION}

Bioresins incorporating up to $60 \%$ weight of humins as a biorefinery by-product have been designed and synthesized. These formulations also feature ELO, a vegetable epoxidized oil, leading to resins with a bio-sourced content up to $70 \%$ in weight. The humin-based bioresins present a broad $\tan \delta$ interval from $\sim 10$ to $60{ }^{\circ} \mathrm{C}$, showing the potential of the proposed formulations to produce materials from elastic to rigid ones. They also have good thermal stability, with $\mathrm{T}_{\mathrm{d} 5 \%}$ values from 250 to $300{ }^{\circ} \mathrm{C}$. The hardness of the resulting materials can be controlled, and in the synthesized bioresins, it varies between $64 \mathrm{~A}$ and $49 \mathrm{D}$, from elastomers to rigid thermosets. This type of materials adheres to the principles of circular economy, in which a byproduct finds a new life as the main component of high value-added materials.

ACKNOWLEDGEMENTS: The authors acknowledge the financial support received from European Commission through the RECYSITE project LIFE15 ENV/BE/000204.

\section{REFERENCES}

1 https://recysite.eu/

2 A. Schweizer, Rec. Trav. Chim., 57, 345 (1938), https://doi.org/10.1002/recl.19380570402

3 A. Schweizer, Rec. Trav. Chim., 39, 781 (1940)

4 R. Van Putten, J. C. Van Der Waal, E. De Jong, C. B. Rasrendra, H. J. Heeres et al., Chem. Rev., 113, 1499 (2013), https://doi.org/10.1021/cr300182k

5 E. De Jong, P. Walsh and M. Wellisch, Biofuels Bioprod. Bioref., 6, $606 \quad$ (2012), https://doi.org/10.1002/bbb.1360

6 E. De Jong, T. Vijlbrief, R. Hijkoop, G. M. Gruter and J. C. Van Der Waal, Biomass Bioenerg., 36, 151 (2012), https://doi.org/10.1016/j.biombioe.2011.10.034
7 A. Mija, E. de Jong, J. C. van der Waal and G. van Klink, PCT Int. Appl. 2017, WO 2017074183 A1 20170504

8 P. Tosi, G. P. M. van Klink, A. Celzard, V. Fierro, L. Vincent et al., ChemSusChem, 11, 2797 (2018), https://doi.org/10.1002/cssc.201800778

9 R. Dinu and A. Mija, Green Chem., 2019, https://doi.org/10.1039/C9GC01813A

10 C. Cantarutti, R. Dinu and A Mija, Biomacromolecules, 2019 , https://doi.org/10.1021/acs.biomac.9b01248

11 A. Mija, J. C. van der Waal, J.-M. Pin, N. Guigo and E. de Jong, Constr. Build. Mater., 139, 594 (2017), http://dx.doi.org/10.1016/j.conbuildmat.2016.11.019

12 J.-M. Pin, N. Guigo, A. Mija, L. Vincent, N. Sbirrazzuoli et al., ACS Sustain. Chem. Eng., 2, 2182 (2014), https://doi.org/10.1021/sc5003769

13 I. van Zandvoort, Y. Wang, C. B. Rasrendra, E. R. H. van Eck, P. C. A. Bruijnincx et al., ChemSusChem, 6, 1745 https://doi.org/10.1002/cssc.201300332

14 M. N. Belgacem and A. Gandini, "Monomers, Polymers and Composites from Renewable Resources", Elsevier, Amsterdam, 2008, https://www.elsevier.com/books/monomers-polymersand-composites-from-renewable-

resources/belgacem/978-0-08-045316-3

15 G. Lligadas, J. C. Ronda, M. Galia and V. Cadiz, Biomacromolecules, 11, $2825 \quad$ (2010), https://doi.org/10.1021/bm100839x

16 H. N. Rabetafika, M. Paquot and P. Dubois, Biotechnol. Agron. Soc. Environ., 10, 185 (2006), https://pdfs.semanticscholar.org/6d38/5d738b44758c3 745b066d60e326e93aca5d1.pdf

17 V. Sharma and P. P. Kundu, Prog. Polym. Sci., 33, 1199

(2008)

https://doi.org/10.1016/j.progpolymsci.2008.07.004

18 F. S. Guner, Y. Yagcib and A. T. Erciyesa, Prog. Polym. Sci., 31, 633 (2006), http://dx.doi.org/10.1016/j.progpolymsci.2006.07.001

19 A. Gandini, Macromolecules, 41, 9491 (2008), https://doi.org/10.1021/ma801735u

20 C. K. Williams and M. A. Hillmeyer, Polym. Rev., 48, 1 (2008),

https://www.tandfonline.com/doi/full/10.1080/155837 20701834133

21 M. S. Fedoseev, L. F. Derzhavinskaya and V. N. Strel'nikov, Russ. J. Appl. Chem., 83, 1408 (2010), https://doi.org/10.1134/S107042721008015X

${ }_{22}$ Q. Luo, M. Liu, Y. F. Xu, M. Ionescu and Z. S. Petrovic, Macromolecules, 44, 7149 (2011), https://doi.org/10.1021/ma201366e

23 N. Boquillon, J. Appl. Polym. Sci., 101, 4037 (2006), https://doi.org/10.1002/app.23133

24 N. Boquillon and C. Fringant, Polymer, 41, 8603 (2000), https://doi.org/10.1016/S0032-3861(00)002561

25 A. Gandini, in "Epoxy Polymers", edited by J. P. Pascault and R. J. J. Williams, Wiley-VCH 
GmbH\&Co. KGaA, Weinheim, 2010, pp. 55-76, https://doi.org/10.1002/9783527628704.ch4

26 J. Clayden, N. Greeves, S. Warren and W. Peter, "Organic Chemistry", $1^{\text {st }}$ ed., Oxford, Oxford University Press, 2000,

https://global.oup.com/ukhe/product/organicchemistry-9780199270293?cc=ro\&lang=en \&

27 J.-M. Pin, N. Sbirrazzuoli and A. Mija, ChemSusChem, $\quad \mathbf{8}, \quad 1232$

https://doi.org/10.1002/cssc.201403262 (2015) 